\title{
Electrochemical Behavior Investigation of Cysteine on Nickel Corrosion in Acidic Medium
}

\author{
H. Saifi ${ }^{* a b}$, S. Ouchenane ${ }^{c}$, R. Bourenane ${ }^{d}$, S.Boukerche ${ }^{e}$, S. Joiret ${ }^{a}$ and H. Takenouti ${ }^{a}$
}

a Laboratoire Interfaces et Systèmes Électrochimiques (LISE), CNRS - Sorbonne Université, UMR 8235, 4 Place Jussieu, 75252 Paris Cedex 05, France;

b Laboratory of Inorganic Materials Chemistry, Badji Mokhtar University of Annaba BP 12, Annaba 23000, Algeria.

c Laboratory of Surfaces Engineering, Badji Mokhtar University of Annaba BP 12, Annaba 23000, Algeria;

d Laboratory of Industrial Mechanics, Badji Mokhtar University of Annaba BP 12, Annaba 23000, Algeria;

e Department of Material Sciences-University Mohamed Cherf Messaadia of Souk Ahras, Algeria.

\section{Abstract}

The corrosion inhibition of nickel in $0.5 \mathrm{M} \mathrm{H}_{2} \mathrm{SO}_{4}$ by cysteine was investigated with various electrochemical methods and surface observations by SEM. The cyclic voltammetry revealed that the current density is the highest in absence of the cysteine and decreases with increasing inhibitor concentration. The cysteine is an anodic inhibitor. The polarization and electrochemical impedance spectroscopy showed that the cysteine has a poor inhibitive effect. The surface observation by scanning electron microscope corroborates the addition of cysteine has no significant improvement of the surface morphology of nickel electrode in $0.5 \mathrm{M} \mathrm{H}_{2} \mathrm{SO}_{4}$. Results obtained by different methods corroborate each other.

Keywords: Polarization curves, EIS, Organic Inhibitor, adsorption mechanism. 


\section{Introduction}

Nickel and nickel containing alloys are one of the most important materials for industrial applications. Main properties of nickel are similar to iron. The corrosion of nickel in aqueous electrolytes has been the subject of numerous studies, motivated by the high technological importance of Ni-containing alloys, such as stainless steels and other corrosion resistant alloys $[1,2]$. Acid solutions are frequently used for pickling of undesired scale and rust in several industrial processes. Because of its anti-scaling ability, sulphuric acid is widely used to clean the metals and its alloys in various pickling bathes [3]. Although nickel is known as corrosion resistant metal in many aggressive media, it corrodes, nevertheless, at a significant rate in presence of mineral acids or in neutral medium [4].

The use of inhibitors is one of the most efficient methods to mitigate the corrosion of metals. The interaction of metal with inhibitor allows modifying the characteristics of the metal surface and making it more resistant to an aggressive environment. The literature devoting to corrosion inhibition by organic compounds is numerous. The inhibitory action of nickel and its alloys in acidic media by various organic and inorganic inhibitors has been widely studied [5-9].

The most effective organic inhibitors are those compounds containing heteroatoms like nitrogen, oxygen, sulphur and phosphorus [10]. The inhibitory action of these molecules is accompanied by their adsorption on the metal surface. Free electron pairs of heteroatoms i.e. $\pi$-electrons, are readily available for sharing to form a bond and act as nucleophile centres of inhibitor molecules. This negative charge facilitates the adsorption process over the metal surface, whose atoms act as electrophile. For instance it was shown that $\mathrm{N}$ containing compounds tend to preferentially adsorb on cathodic sites on iron in acidic solution whereas S-containing compounds mainly function by chemisorption on anodic sites [11-13].

Though many inhibitor compounds showed a good anticorrosive activity, most of them are toxic or harmful to both human beings and environment. The safety and environmental 
problems of corrosion inhibitors identified in industries are always a global concern. These toxic or noxious effects lead to the use of ecological and harmless anticorrosive compounds.

Nowadays many alternative eco-friendly corrosion inhibitors are developed; they range from rare earth elements [14-16] to organic compounds [17-20], among others amino acids.

Amino-acids are innocuous, biodegradable, relatively inexpensive and completely soluble in aqueous media. The number of publications about the inhibitory effect of amino acids on corrosion of metals increases [21-25]. In particular, cysteine $\left(\mathrm{HSCH}_{2} \mathrm{CHNH}_{2} \mathrm{COOH}\right)$ stands as one of the most promising candidate. Because this molecule contains the thiol group [-SH], the amino group [- $\left.\mathrm{NH}_{2}\right]$ and the carboxyl group [-COOH].

This paper focuses on the effect of eco-friendly and innoxious cysteine as nickel corrosion inhibitor in sulphuric acid. We have recently reported the action of cysteine for the corrosion inhibition of copper and cupronickel in $0.5 \mathrm{M} \mathrm{H}_{2} \mathrm{SO}_{4}$, and the inhibitory power is found to be remarkable [26]. For this reason, we aimed at to collect the inhibitory performance of cysteine on the corrosion of nickel in $0.5 \mathrm{M} \mathrm{H}_{2} \mathrm{SO}_{4}$. This study was carried out by electrochemical methods; evolution of the open circuit corrosion potential, cyclic voltammetry; potentiodynamic polarization curves, and electrochemical impedance spectroscopy (EIS). Morphological changes on the corroded nickel surface were completed by scanning electron microscopy (SEM).

\section{Experimental methods}

\subsection{Electrodes and electrolysis cell}

A classical three-electrode cell made of cylindrical borosilicate was used for electrochemical experiments. The counter-electrode was a large platinum grid. The reference electrode was a saturated mercurous sulphate electrode (SSE). The potential will be given with respect to this reference electrode without correction for ohmic drop. The working electrode was prepared of a cylindrical nickel rod of $0.2 \mathrm{~cm}^{2}$ cross-sectional area from Good fellow (purity 99.999\%). The lateral part of the nickel rod was coated by a cataphoretic paint layer (PPG; W781-I1292+W975-G292), cured at $150{ }^{\circ} \mathrm{C}$ for $30 \mathrm{~min}$ to avoid the infiltration of corrosive solution in the lateral part of the electrode. Then, the nickel cylinder was embedded into an epoxy resin (Buhler, Epoxycure ${ }^{\mathrm{TM}}$ ). 
Prior to measurements, working electrode was mechanically abraded with emery paper up to grade 4000 to yield a smooth and planar surface. Then, sample was thoroughly cleaned using acetone, rinsed with de-ionized water, and dried by argon or nitrogen flow.

Subsequently, the sample was transferred into the electrochemical cell. The electrode was set near the centre of cylindrical cell without rotation.

\subsection{Corrosion test solutions}

The electrolyte used was $0.5 \mathrm{M} \mathrm{H}_{2} \mathrm{SO}_{4}$ at room temperature prepared of analytical grade sulphuric acid and doubly distilled water in thermodynamic equilibrium to air; neither stirring nor bulling of inert gas were made. The inhibitor used was L-cysteine $\left(\mathrm{HSCH}_{2} \mathrm{CHNH}_{2} \mathrm{COOH}\right)$ at two concentrations, $10^{-3}$ and $10^{-2}$ mole $\mathrm{L}^{-1}$. The molar mass of this compound is 121.16 . This substance will be called also as Cys.

\subsection{Electrochemical devices and experimental procedures}

Voltammetric measurements were performed using a potentiostat-galvanostat $\left(\right.$ METROHM $^{\circledR}$, AUTOLAB PGSTAT 20 ${ }^{\mathrm{TM}}$ ) monitored by GPES software. The cyclic voltammetry were carried out with a scan rate of $10 \mathrm{mV} \mathrm{s}^{-1}$. The potentiodynamic polarization curves were obtained with a scan rate of $0.5 \mathrm{mV} \mathrm{s}^{-1}$ with two independent measurements; one the potential scan towards more negative direction from $10 \mathrm{mV}$ more positive from the open

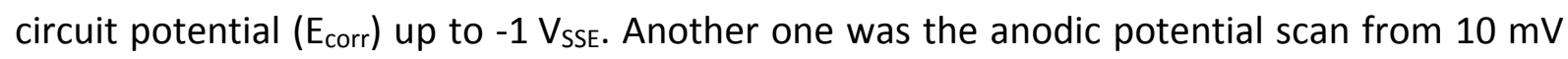
more negative to the open circuit potential up to $-0.3 \mathrm{~V}_{\mathrm{SSE}}$.

Electrochemical Impedance Spectroscopy (EIS) measurements were realized using a potentiostat (SOTELEM ${ }^{\circledR}$ PG-STAT.Z1) at open circuit corrosion potential, $E_{\text {corr, coupled with a }}$ frequency response analyser (SOLARTRON ${ }^{\circledR}$ SI 1255). For all EIS measurements, perturbing signal was the sine-wave signal of which amplitude was $10 \mathrm{mV}_{\text {rms. }}$. The frequency range examined was from $10 \mathrm{kHz}$ to $10 \mathrm{mHz}$. The impedance spectra were represented by an electrical equivalent circuit, and the values of these elements were determined by homemade software with a simplex algorithm. 


\subsection{SEM observations}

For morphological observations, the samples were prepared and treated as describe above and immersed in the test solution during $24 \mathrm{~h}$. The surface state was examined using scanning electronic microscope (LEICA ${ }^{\circledR}$ STEREOSCAN 440).

\section{Results and discussion}

\subsection{Evolution of open circuit potential}

The time evolution of the open circuit corrosion potential ( $E_{\text {corr }}$ ) for nickel in $0.5 \mathrm{M} \mathrm{H}_{2} \mathrm{SO}_{4}$ in absence and in presence of different concentrations of cysteine $\left(10^{-3}-10^{-2} \mathrm{M}\right)$ during one hour is illustrated in Figure 1.

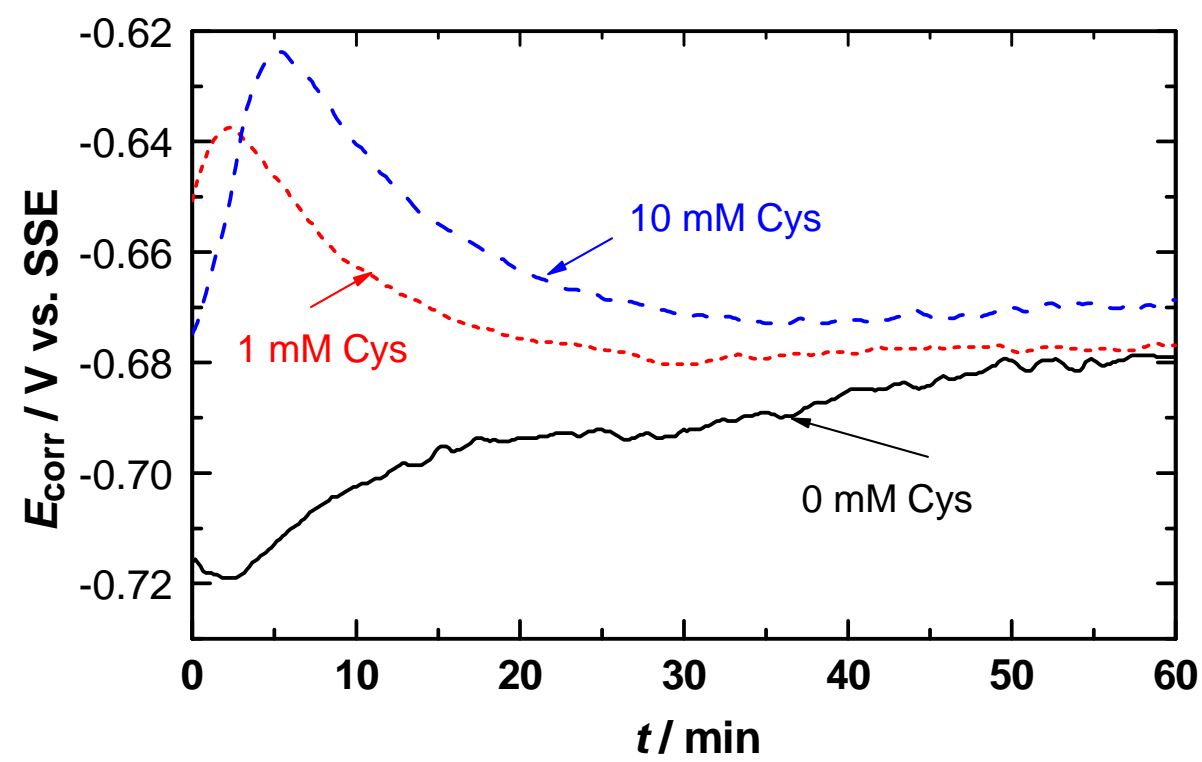

Figure 1: Evolution the corrosion potential of a nickel electrode in aerated $0.5 \mathrm{M} \mathrm{H}_{2} \mathrm{SO}_{4}$ without and with $10^{-3}$ or $10^{-2} \mathrm{M}$ Cys.

In absence of Cys, $E_{\text {corr }}$ shifts towards more positive direction. In its presence, the evolution of $E_{\text {corr }}$ is different; first a marked increase of $E_{\text {corr }}$ during the first 5 or 10 min after immersion followed by its decrease. The steady state potential is reached after about 30 minutes of immersion. At the steady state, $E_{\text {corr }}$ showed a similar value in absence and in presence of Cys. 


\subsection{Cyclic voltammetry}

Figure 2 shows the effect of Cys on the cyclic voltammograms (CV) of $\mathrm{Ni}$, obtained in $0.5 \mathrm{M}$ $\mathrm{H}_{2} \mathrm{SO}_{4}$ solution, without and with $10^{-3}$ or $10^{-2} \mathrm{M}$ Cys. The potential scan started from $-1 \mathrm{~V}_{\text {SSE }}$ up to $+0.12 \mathrm{~V}_{\text {SSE, }}$, then returned to $-1 \mathrm{~V}_{\text {SSE. The }}$ Thetential scan rate was $10 \mathrm{mV} \mathrm{s}^{-1}$.

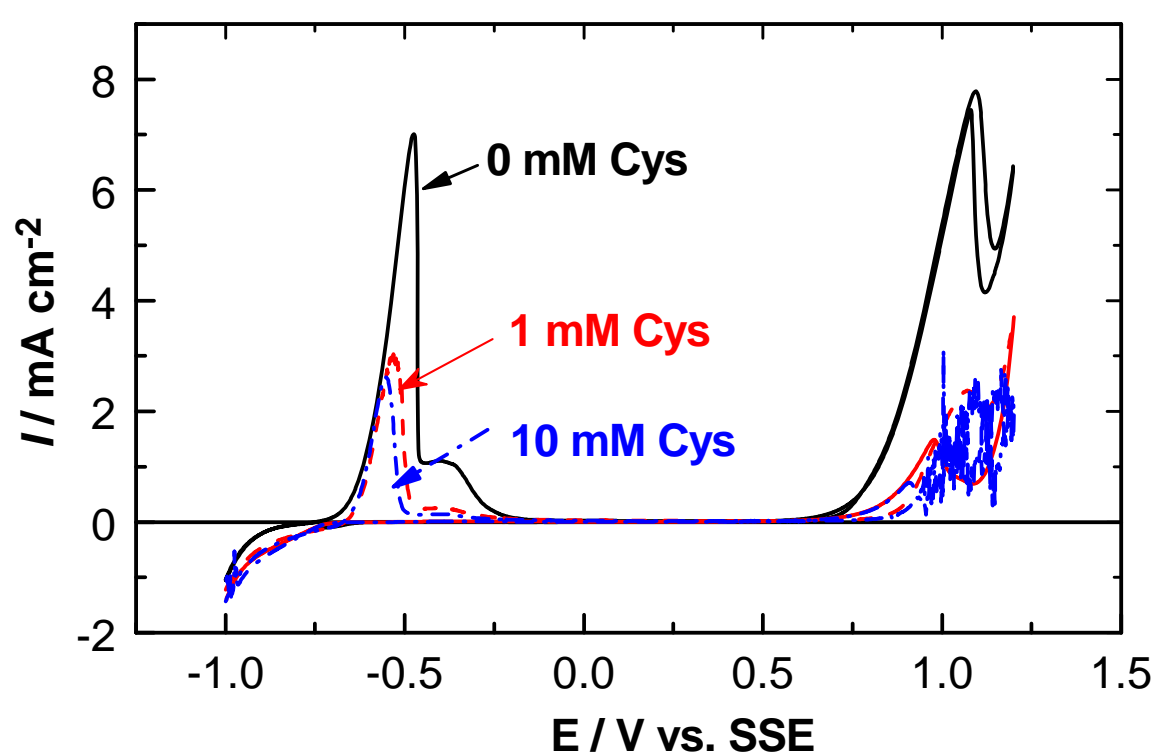

Figure 2: Cyclic voltammograms of $\mathrm{Ni}$ in $0.5 \mathrm{M} \mathrm{H}_{2} \mathrm{SO}_{4}$ without and with $10^{-3}$ or $10^{-2} \mathrm{M}$ Cys

During anodic scan, the shape of the CV without Cys is consistent with that reported in other studies. According to the literature, the form of $\mathrm{CV}$ is related to the potential scan rate. At a high scanning rate the $\mathrm{CV}$ is characterized by a single anodic peak before passivity state. In contrast below $10 \mathrm{mV} \mathrm{s}^{-1}$ the appearance of two peaks was observed [27].

For the sharp peak located at lower anodic potential in absence of Cys, the peak potential $E_{p 1}$ is $-0.475 V_{\text {SSE }}$ and the current density $I_{p 1}=7.01 \mathrm{~mA} \mathrm{~cm}^{-2}$. In presence of Cys, this peak shift to more negative direction. At Cys concentration [Cys] of $10^{-3} \mathrm{M}, \mathrm{E}_{\mathrm{p} 1}$ and $\mathrm{I}_{\mathrm{p} 1}$ are respectively $-0.533 \mathrm{~V}_{\text {SSE }}$ and $3.07 \mathrm{~mA} \mathrm{~cm}^{-2}$. At [Cys] $=10^{-3} \mathrm{M}, \mathrm{E}_{\mathrm{p} 1}$ and $\mathrm{I}_{\mathrm{p} 1}$ changed to -0.553 $V_{S S E}$ and $2.62 \mathrm{~mA} \mathrm{~cm}^{-2}$. The addition of Cys in $0.5 \mathrm{M} \mathrm{H}_{2} \mathrm{SO}_{4}$ thus hinders the anodic dissolution of nickel and enhances the first passivation process leading to the peak 1. 
Beyond the sharp current peak, the blunt peak leading to the passivation of nickel in a sulphuric acid was observed. The current density of this peak is located at $E_{p 2}=-0.400 V_{\text {SSE }}$ and $\mathrm{I}_{\mathrm{p} 2}=1.11 \mathrm{~mA} \mathrm{~cm}{ }^{-2}$. The addition of Cys does not change significantly this peak position whereas the current density decreases substantially. At $10^{-3} \mathrm{M}$, peak potential is located at $-0.396 \mathrm{~V}_{\text {SSE }}$ for the peak current density of $0.254 \mathrm{~mA} \mathrm{~cm}^{-2}$, and at $10^{-2} \mathrm{M}$, they are respectively $-0.398 \mathrm{~V}_{\text {SSE }}$ and $0.141 \mathrm{~mA} \mathrm{~cm} \mathrm{~cm}^{-2}$. The dissolution of nickel is hindered by the presence of Cys in the electrolyte. This is probably due to the adsorption of Cys on the nickel electrode surface preventing its active dissolution.

During the reverse scan, as it can be seen in Figure 3, the current density is much lower due to the presence of the passive film. The reduction of $\mathrm{NiO}$ reveals often by a cathodic peak at about $-0.5 \mathrm{~V}_{\mathrm{SSE}}$, but this phenomenon is not observed in this work.

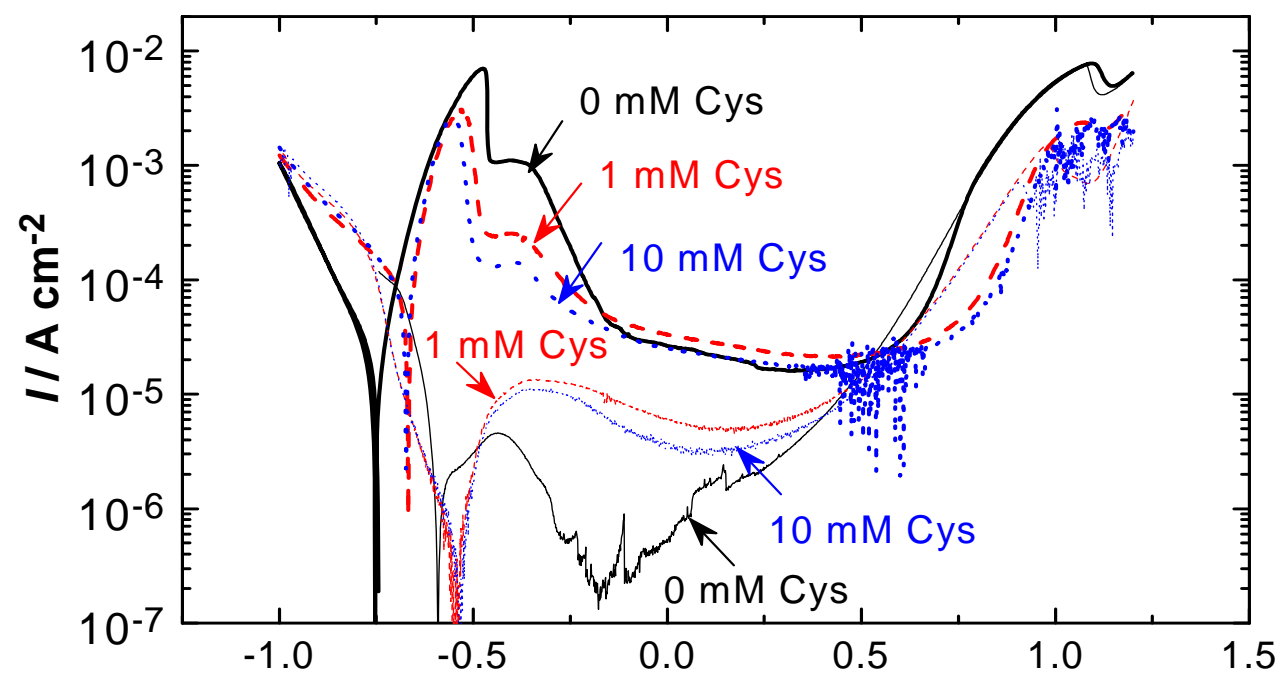

E I V vs. SSE

Figure 3: Cyclic voltammograms in semi logarithmic plane of the nickel electrode in $0.5 \mathrm{M} \mathrm{H}_{2} \mathrm{SO}_{4}$ without and with $10^{-3}$ or $10^{-2} \mathrm{M}$ Cys

(The same results to those presented in Figure 2)

Figure 3 presents the results of Figure 2 in a semi-logarithmic scale, so that the current density during the back-scan can be evaluated readily. It can be noticed that in the passivity domain, the current density is smallest in absence of inhibitor, which may indicate that the presence of Cys somewhat destabilized the passive film. In other terms, the decrease of the peak current density is more closely linked to the hindering of the anodic dissolution rather 
that the enhancement of the passive film formation. This aspect will be further discussed in \$3.3.2.

\subsection{Potentiodynamic polarization measurements}

The typical anodic and cathodic polarization curves of nickel in $0.5 \mathrm{M} \mathrm{H}_{2} \mathrm{SO}_{4}$ in absence and in presence of $1 \mathrm{mM}$ or $10 \mathrm{mM}$ of Cys are shown in Figures 4 and 5 . The potential scan rate was much slower than that used for cyclic voltammetry, i.e. $0.5 \mathrm{mV} \mathrm{s}^{-1}$ instead of $10 \mathrm{mV} \mathrm{s}^{-1}$.

\subsubsection{Cathodic scan}

It can be seen in Figure 4 that the cathodic reaction is controlled by the convective diffusion

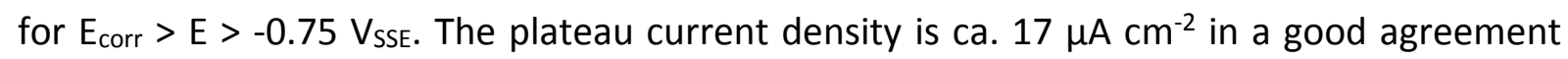
with the reduction of dissolved oxygen controlled by diffusion for a stagnant solution. Its reaction can be expressed, similar to the case on Fe electrode [28]:

$$
\mathrm{O}_{2}+2 \mathrm{H}_{2} \mathrm{O}+4 \mathrm{e}^{-} \rightarrow 4 \mathrm{OH}^{-}
$$

Therefore, the spontaneous corrosion current density will be mainly controlled by this process.

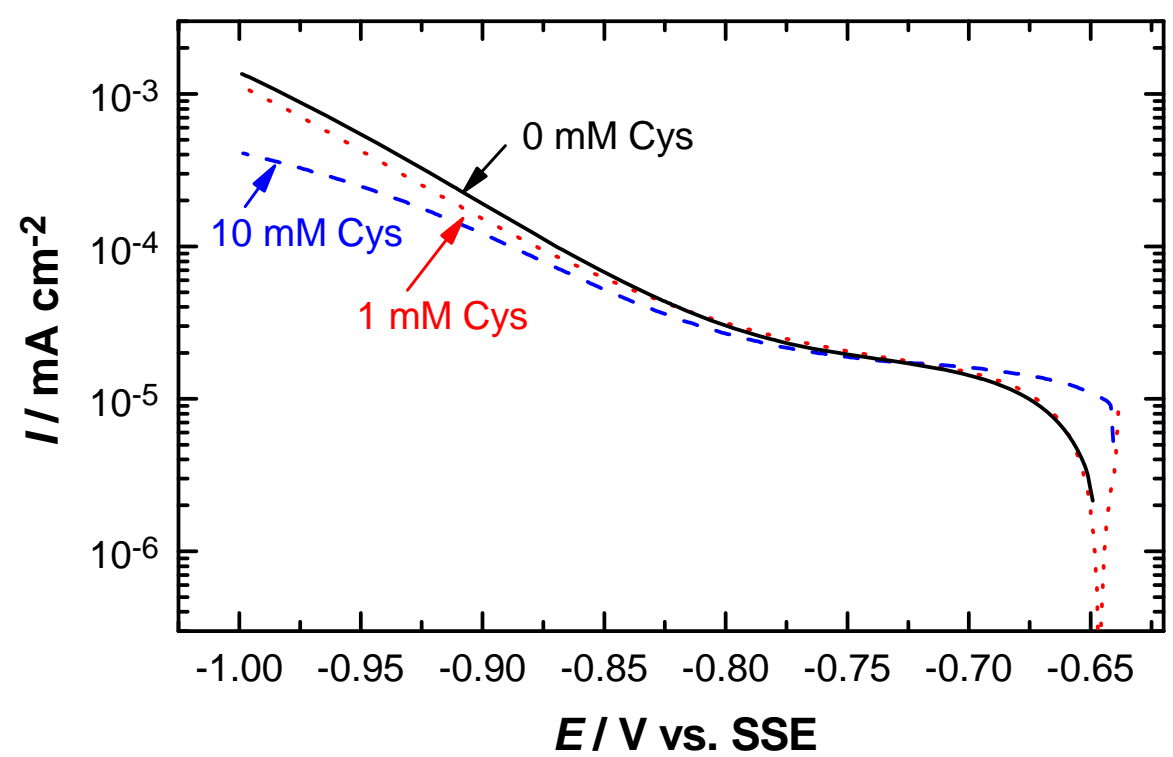

Figure 4: Cathodic polarization curves of nickel in $0.5 \mathrm{M} \mathrm{H}_{2} \mathrm{SO}_{4}$ without and with $10^{-3}$ or $10^{-2} \mathrm{M}$ Cys; scan rate $0.5 \mathrm{mV} \mathrm{s}^{-1}$ 
For potentials more negative than $-0.8 \mathrm{~V}_{\mathrm{SSE}}$, the cathodic reaction increases linearly in $\log (\mathrm{I})-$ E plot. This reaction is allocated to the hydrogen evolution reaction by the reduction of hydronium ions according to Reaction (2):

$$
2 \mathrm{H}_{3} \mathrm{O}^{+}+2 \mathrm{e}^{-} \rightarrow \mathrm{H}_{2}+2 \mathrm{H}_{2} \mathrm{O}
$$

The cysteine reduces clearly the hydrogen evolution reaction rate and has no effect on the reduction of dissolved oxygen, Reaction (1).

\subsubsection{Anodic scan}

The polarization curves collected during the anodic scan are presented in Figure 5. Compared with Figure 2, in absence of Cys, it can be noticed that the current density of the first peak is much smaller and the current density of the second peak is higher for this slow potential scan.

Anodic dissolution of nickel in sulphuric media has been studied extensively by de Gromobov and Shreir [29]. The first step of the Ni dissolution was attributed to the formation of the adsorbed reaction intermediate species $\mathrm{NiOH}_{\mathrm{ad}}$ [30-33]:

$$
\mathrm{Ni}+\mathrm{H}_{2} \mathrm{O} \rightarrow \mathrm{NiOH}_{\mathrm{ad}}+\mathrm{H}^{+}+\mathrm{e}^{-}
$$

This intermediate species $\mathrm{NiOH}_{a d}$ will precede two reactions. First, oxidation of the intermediate into $\mathrm{Ni}^{2+}$ i.e. the active dissolution leading to the corrosion of $\mathrm{Ni}$ :

$$
\mathrm{NiOH}_{\mathrm{ad}}+\mathrm{H}^{+} \rightarrow \mathrm{Ni}^{2+}+\mathrm{e}^{-}+\mathrm{H}_{2} \mathrm{O}
$$

On the other hand, oxidation and deprotonation of the same intermediate, leading to the passive species $\mathrm{NiO}$ :

$\mathrm{NiOH}_{\mathrm{ad}} \leftrightarrow \mathrm{NiO}+\mathrm{H}^{+}+\mathrm{e}^{-}$ 


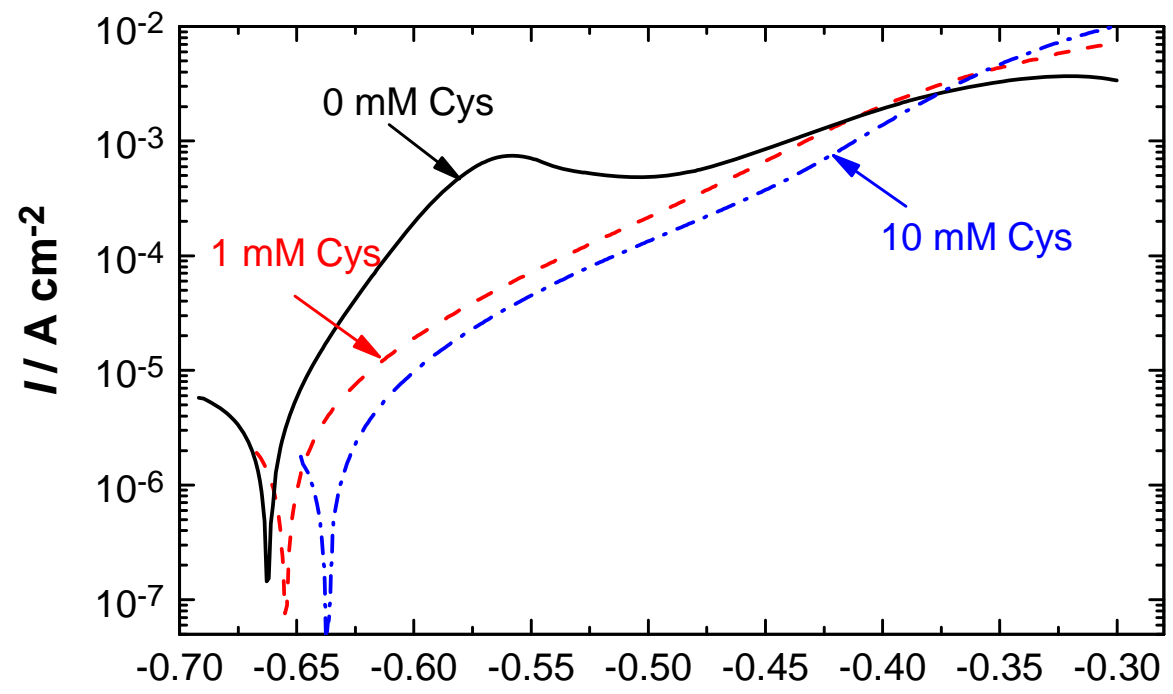

EIV vs. SSE

Figure 5: Anodic polarization curves of nickel in $0.5 \mathrm{M} \mathrm{H}_{2} \mathrm{SO}_{4}$ without and with $10^{-3}$ or $10^{-2} \mathrm{M}$ Cys; scan rate $0.5 \mathrm{mV} \mathrm{s}^{-1}$

The Nernst equilibrium potential of $\mathrm{Ni} \leftrightarrow \mathrm{NiO}$ is $-0.53 \mathrm{~V}_{\text {SSE, }}$ corresponding to the first peak observed by cyclic voltammetry (Figure 2), since this peak is located at $-0.559 \mathrm{~V}_{\text {SSE }}$ and the current density equal to $0.746 \mathrm{~mA} \mathrm{~cm}^{-2}$. This current density is about one tenth' of that observed with the potential scan equal to $10 \mathrm{mV} \mathrm{s}^{-1}$.

The second current peak is located at $-0.320 \mathrm{~V}_{\text {SSE }}$ and the current density is $3.58 \mathrm{~mA} \mathrm{~cm} \mathrm{~cm}^{-2}$. This current density is about three times as high as that observed with a fast potential scan.

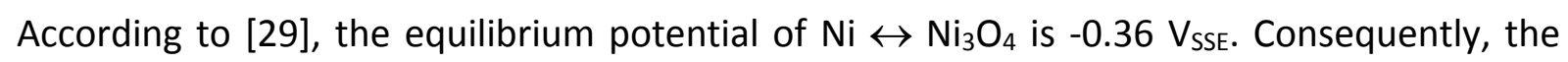
second current peak can be allocated to the formation of $\mathrm{Ni}_{3} \mathrm{O}_{4}$ though the following reaction:

$$
\mathrm{NiO}+2 \mathrm{Ni}+3 \mathrm{H}_{2} \mathrm{O} \leftrightarrow \mathrm{Ni}_{3} \mathrm{O}_{4}+6 \mathrm{H}^{+}+6 \mathrm{e}^{-}
$$

The addition of Cys reduces the anodic current density near $E_{c o r r}$, and induces the disappearance of the first current peak. Besides, the second current peak observed by cyclic voltammetry is no longer observed clearly in the potential range used here, but I-E curve bends slightly towards a smaller current density. In other words, the current density of the first peak decreases whereas that of the second peak increases when the potential scan becomes slower. As a whole, in presence of Cys, the first peak disappears. 
The cysteine is thus an anodic inhibitor for the dissolution process in Reaction (3) while it hinders the formation of $\mathrm{Fe}_{3} \mathrm{O}_{4}$ by Reaction (6). Such a phenomenon could be linked on one hand to the formation $\mathrm{Ni}$-Cys adsorbate or that of insoluble a Ni-Cys complex that may thwart the formation of the passivity films.

\subsubsection{Corrosion current density by voltammetry}

Close to the corrosion potential $E_{\text {corr, }}$ the first Stern-Geary relationship [34] may be applied, provided that the both anodic and cathodic processes, are purely additive, and that each processes follows an exponential law with respect to the potential. Then, the overall current density is given according to the following relation:

$$
I=I_{\text {corr }} \cdot\left\{\exp \left[b_{a}\left(E-E_{c o r r}\right)\right]-\exp \left[b_{c}\left(E-E_{c o r r}\right)\right]\right\}
$$

Where $I_{c o r r}$ is corrosion current density $\left(A \mathrm{~cm}^{-2}\right), b_{a}$ and $b_{c}$ are respectively the anodic and cathodic Tafel constants $\left(\mathrm{V}^{-1}\right)$.

It will be worth to mention that sometimes, the Tafel constant is allocated to the slope of polarization curves in $\log (\mathrm{I})$ - E scale, i.e. Tafel slope in unit of $\mathrm{V} \mathrm{dec}^{-1}$. Let this constant be represented by $\beta$, the two constants $b$ and $\beta$ are linked through the following expression:

$$
b=\frac{\ln (10)}{\beta}
$$

$I_{\text {corr, }} E_{c o r r}, b_{a}$ and $b_{c}$, were evaluated from the experimental results by using a user defined function of "Non-linear least squares curve fit" implemented in the graphic software used (Origin $^{\mathrm{TM}}$, OriginLab ${ }^{\circledR}$ ). Since the anodic polarization may modify the adsorption of Cys by the dissolution of substrate nickel during an initial polarization of cathodic scan, the anodic scan was used to apply Equation (7). 40 points, i.e. $40 \mathrm{mV}$ from the starting potential used for this calculation.

Figure 6a shows the polarization curve obtained in absence of and in presence of Cys. In can be remarked that the polarization curve show a smaller slope when the concentration of Cys increases. Figure $6 \mathrm{~b}$ displays the same data but in a semi-logarithmic scale, so called Tafel plot. The non linear parameter fittings were carried out with the absolute value of the logarithm of current density, $\log (|I|)$. The results of fitting (in curve) are overlaid on the 
experimental data (in symbols). It can be seen in Figure 6, a good agreement between the calculated and the fitted polarization data as well for Figure $6 a$ as Figure $6 \mathrm{~b}$.

Besides, in Figure 6b, one may notice that the extrapolation of the cathodic branches for various Cys concentration tend to overlap. This remark confirms that the cathodic current density near $E_{\text {corr, }}$ is determined mainly by the limiting diffusion current density of the dissolved oxygen as stated on Figure 4.

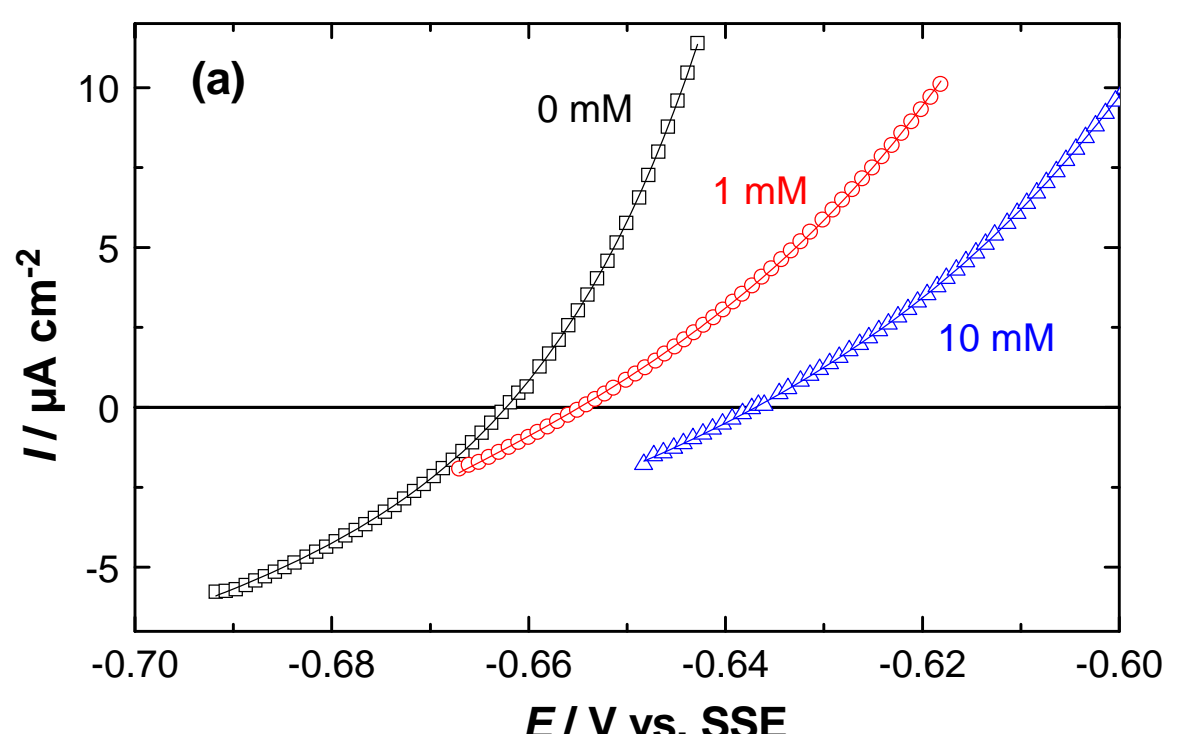

EIV vs. SSE

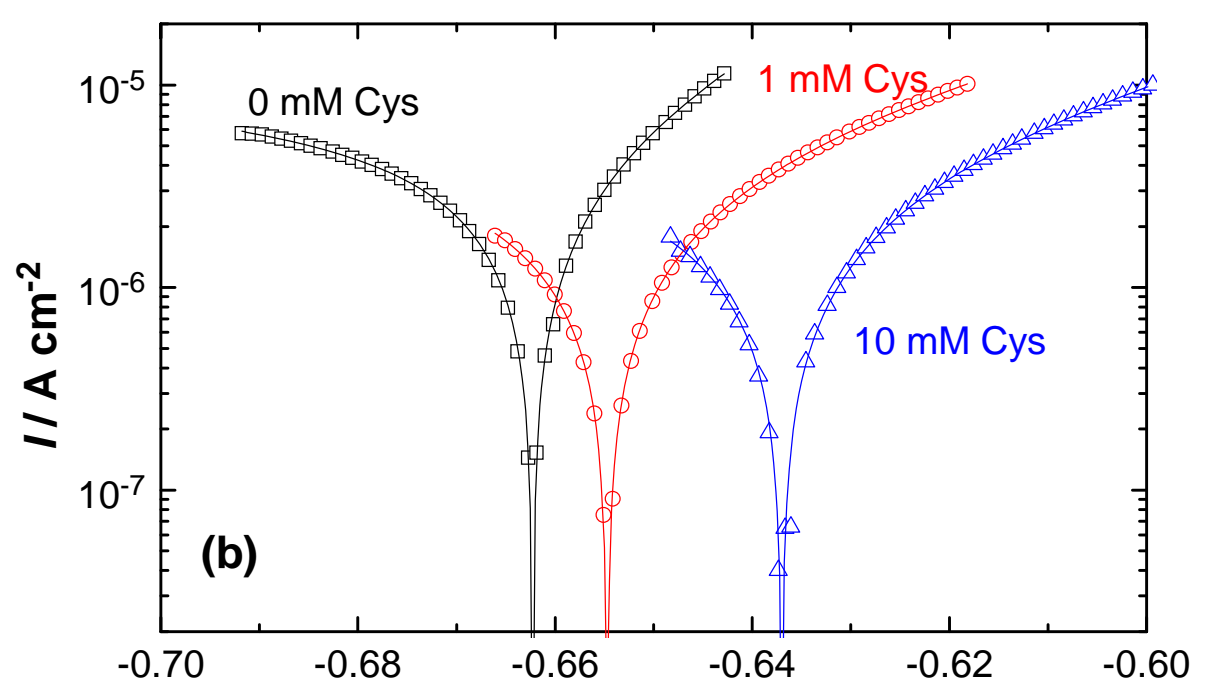

EIV vs. SSE

Figure 6: Comparison between experimental and calculated I-E curves. 
The corrosion rate is thus essentially determined from the anodic polarization curves. The inhibitory efficiency in percent IE(\%) was evaluated from the following relationship:

$$
I E(\%)=100 \cdot \frac{I_{\text {corr }}-I_{\text {corr }}}{I_{\text {corr }}^{0}}
$$

Where $\mathrm{I}^{0}$ corr and $\mathrm{I}_{\text {corr }}$ denote the corrosion current densities, in absence and in presence of Cys, respectively. Table 1 summarizes the results of non-linear regression calculation with I-E curve and $\log (\mathrm{I})$-E curves. They are denoted by suffix "lin" or "log" respectively.

Table 1: Corrosion parameters determined by non linear regression calculation according to Equation 7 for experimental results

\begin{tabular}{clcccc}
\hline $\begin{array}{c}\text { CCys }] \\
\mathrm{mol} \mathrm{L}^{-1}\end{array}$ & $\begin{array}{l}\mathrm{E}_{\text {corr }} \\
\mathrm{V}_{\text {sse }}\end{array}$ & $\begin{array}{c}\mathrm{I}_{\text {corr lin }} \\
\mu \mathrm{A} \mathrm{cm}{ }^{-2}\end{array}$ & $\mathrm{IE}_{\text {lin }}(\%)$ & $\begin{array}{c}\mathrm{I}_{\text {corr log }} \\
\mu \mathrm{A} \mathrm{cm}{ }^{-2}\end{array}$ & $\mathrm{IE}_{\text {log }}(\%)$ \\
\hline 0 & -0.6623 & $5.22 \pm 0.01$ & - & $5.22 \pm 0.39$ & \\
$10^{-3}$ & -0.6549 & $3.70 \pm 0.25$ & $29.1 \pm 2.0$ & $5.78 \pm 0.31$ & $-10.7 \pm 1.3$ \\
$10^{-2}$ & -0.6370 & $4.95 \pm 0.39$ & $6.03 \pm .04$ & $4.27 \pm 0.24$ & $18.1 \pm 2.4$ \\
\hline
\end{tabular}

The values of inhibitory efficiency $\mathrm{IE}(\%)$ are also included in Table 1 . These values show that Cys for the two concentrations tested inhibits only slightly the corrosion of nickel in acid solutions. This statement corroborates the fact that the cathodic process is determined in major part by the cathodic reaction of dissolved oxygen near $E_{c o r r}$ controlled by the convective diffusion.

The polarization resistance $R_{p}$ was also determined from the slope of the current-potential curve at the corrosion potential:

$$
R_{p}=\left.\frac{\mathrm{d} E}{\mathrm{~d} l}\right|_{E_{c o r r}}
$$

From Equation (7), one gets readily so called the second Stern-Geary equation [31]:

$$
I_{\text {corr }}=\frac{1}{R_{p} \cdot\left(b_{a}-b_{c}\right)}=\frac{B}{R_{p}}
$$


According to the obtained results, polarization resistance gets a higher value with increasing concentration of the cysteine, as can be seen in Figure $6 a$. If the value of $R_{p}$ is considered to determine the corrosion rate with a constant the Stern-Geary coefficient, B, one may have erroneous conclusion on the inhibitory effect of cysteine on the corrosion of nickel in $0.5 \mathrm{M}$ $\mathrm{H}_{2} \mathrm{SO}_{4}$. That is to say, $b_{a}$ and $b_{c}$ are dependent on cysteine concentration.

Figure 7 presents the absolute value of $b_{a}$ and $b_{c}$ determined from linear I-E relationship and those from the Tafel plot (Iig(|I|)-E) for different Cys concentrations. As this is the case for the corrosion current density, with the same data set, the values of parameter obtained by regression calculations are different. However, the comparison of experimental data

(symbols) and fitted data (lines) showed an excellent quality of the fitting procedures. $\mathrm{R}^{2}$ is for the whole cases, greater than 0.9998. The difference observed is probably due to the data treatments, I or $\log (|| \mid)$.

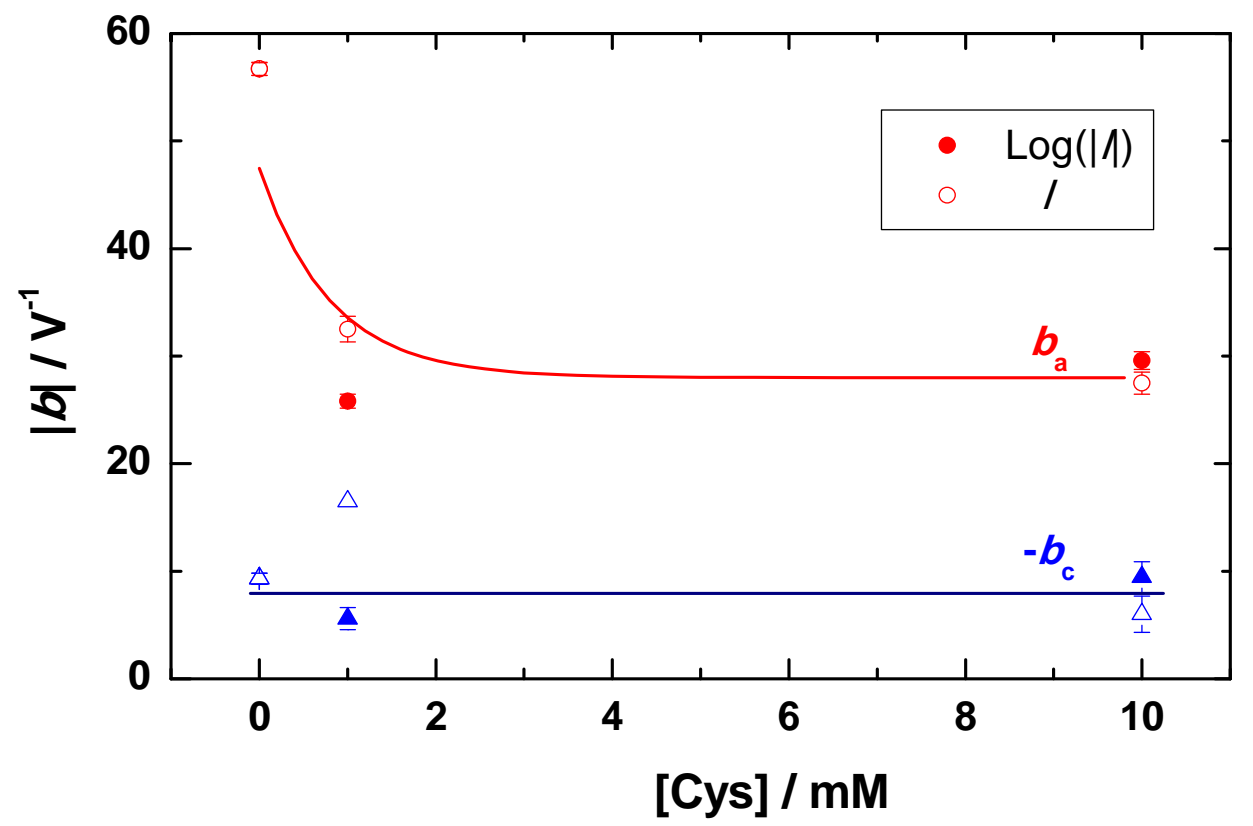

Figure 7: Tafel constants $b_{a}$ and $b_{c}$ are determined from Figures $6 a(I)$ and $6 b(\log (|/|)$ $b_{c}$ varies is little, though scattered, and values about $9 \mathrm{~V}^{-1}$. This small value corresponds well to the system mainly controlled by the limiting diffusion current density. In contrast, $b_{a}$ decreases with increasing [Cys] roughly by an exponential-type decay curve. The presence of cysteine therefore modifies the activation energy of the anodic process, thus the nature of 
anodic reaction itself. The Stern-Geary coefficient B decreases thus with increasing [Cys] which explains the apparent contradiction with $R_{p}$ value and the corrosion current density.

\subsection{Electrochemical impedance spectroscopy}

To obtain additional information on the electrochemical processes taking place at the interface in absence and in presence of Cys, electrochemical impedance measurements were carried out. The electrode was left alone for one hour and then the impedance measurements were started at the open circuit potential $E_{\text {corr }}$ form high to low frequencies.

Figure 8a shows, the impedance spectra in Nyquist plot of Nickel electrode immersed in an aerated $0.5 \mathrm{M} \mathrm{H}_{2} \mathrm{SO}_{4}$ in absence and in presence of Cys $\left(10^{-3}\right.$ or $\left.10^{-2} \mathrm{M}\right)$. One capacitive loop was observed for three cases with a small tail at the low frequency end, $f<0.1 \mathrm{~Hz}$. This

impedance behaviour will be explained by the fact that, in spite of one hour stabilization period, the system was not entirely reached at its steady state.

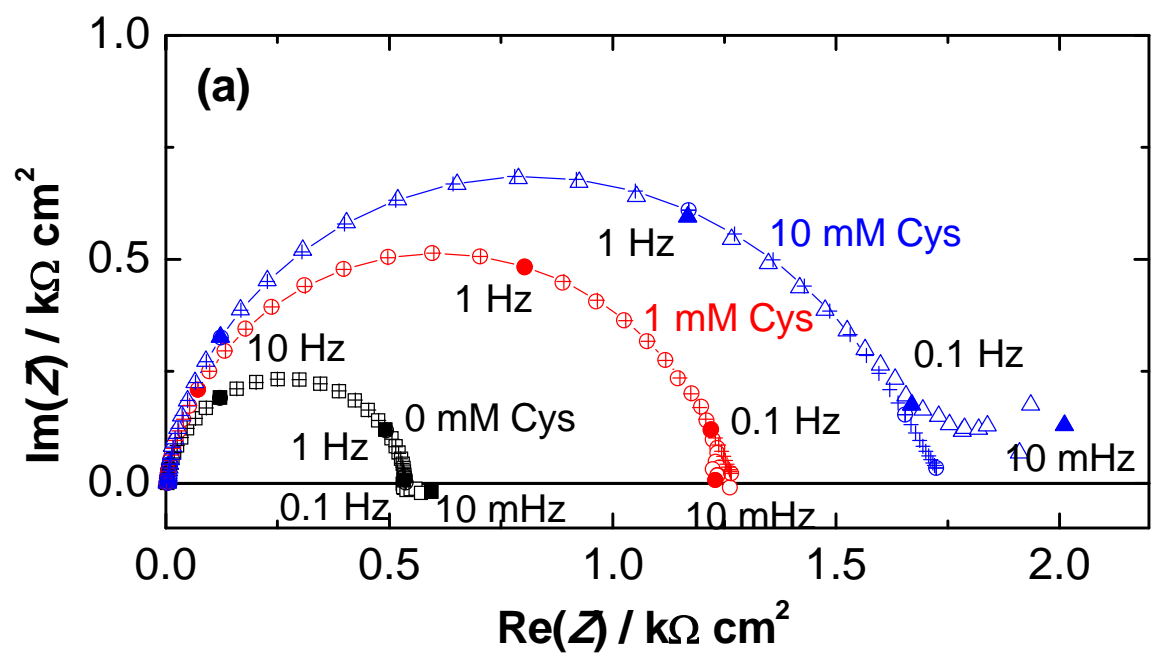




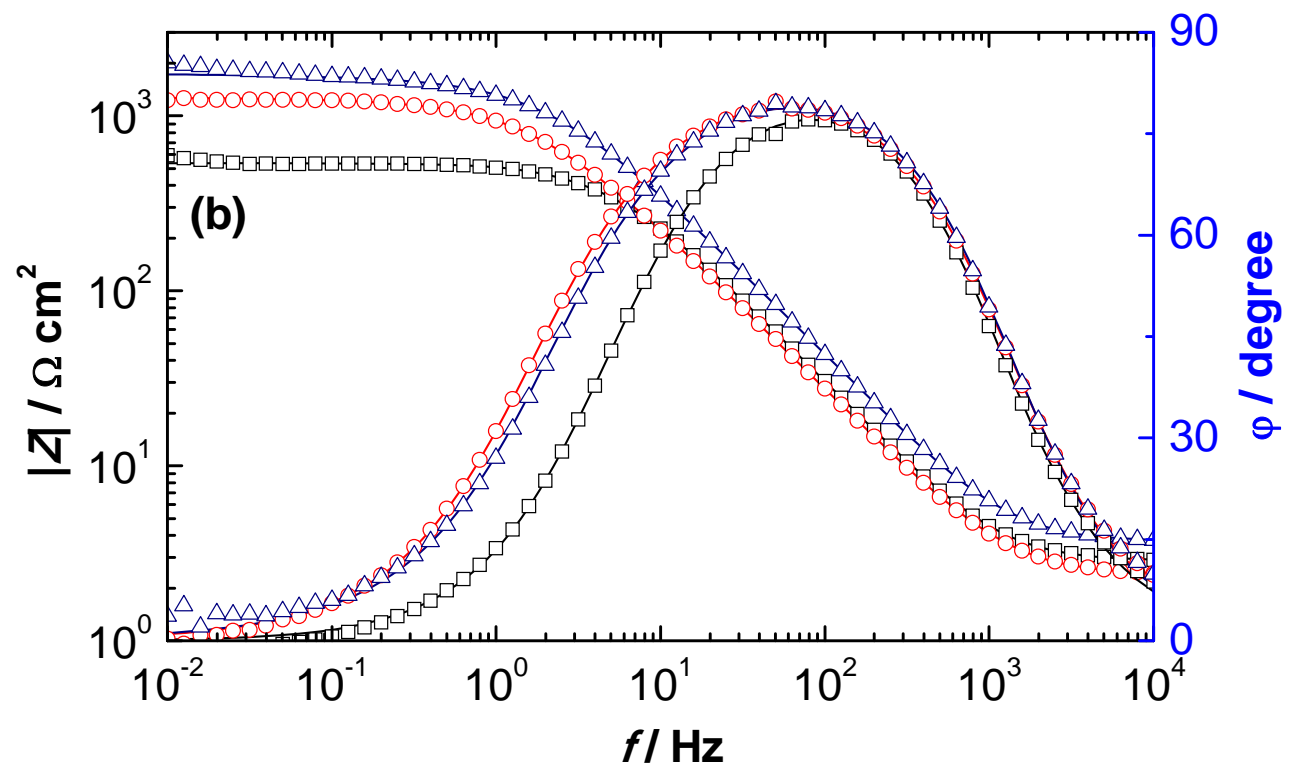

Figure 8: Electrochemical impedance diagrams representing Nyquist (a) and Bode (b) plots of Nickel in $0.5 \mathrm{M} \mathrm{H}_{2} \mathrm{SO}_{4}$ without and with $10^{-3}$ or $10^{-2} \mathrm{M}$ of Cys

In the Bode diagrams, Figure $8 \mathrm{~b}$, only one maximum of phase-shift $\varphi$ at intermediate frequencies is observed in agreement with Nyquist plot exhibiting one capacitive loop.

The maximum phase angle is less than $80^{\circ}$ in agreement with a depressed feature observed in Nyquist plot, Figure 8a. However, the spectra observed in the Nyquist diagram or the phase shifts in the Bode diagram are not well symmetrical. This behaviour suggests the presence of two time constants badly separated. Indeed, a non-linear regression calculation with one time constant revealed a marked systematic error. That is, in the Nyquist plot, around its apex, all calculated points are located above the experimental points, and for low and high frequency extremities, all calculated data are located below the experimental data. Therefore, the presence of two depressed capacitive loops is taken into account. The equivalent electrical circuit with two CPE//R ladder connexion is used as illustrated in Figure 9.

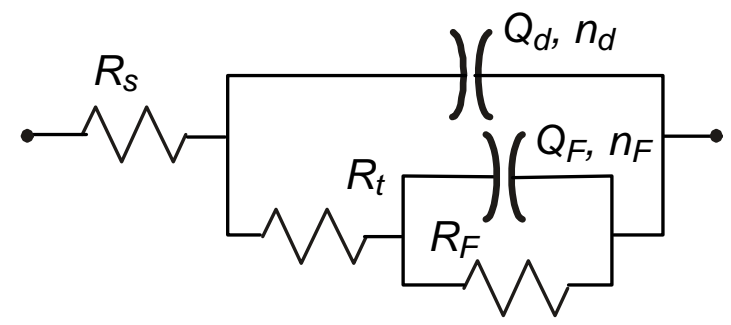

Figure 9: Equivalent electrical circuits used to represent impedance data of Nickel. 
The origin of these, circuit-elements are allocated to:

$\mathrm{R}_{\mathrm{s}}$ : Solution resistance $\left(\Omega \mathrm{cm}^{2}\right)$,

$Q_{d}$ : CPE element associated with the double layer capacitance $\left(\mathrm{F} \mathrm{cm}^{-2} \mathrm{~s}^{\mathrm{n}^{-1}}\right)$,

$\mathrm{R}_{\mathrm{t}}$ : Charge transfer resistance $\left(\Omega \mathrm{cm}^{2}\right)$,

$\mathrm{C}_{\mathrm{F}}$ : Faradaic capacitance due to the surface relaxation of $\mathrm{NiOH}_{\mathrm{ad}}$ or $\mathrm{NIO}\left(\mathrm{F} \mathrm{cm}^{-2} \mathrm{~s}^{\mathrm{n}_{\mathrm{F}}-1}\right)$,

$\mathrm{R}_{\mathrm{F}}$ : Faradaic resistance associated with reactions 3 to $5\left(\Omega \mathrm{cm}^{2}\right)$,

$n_{d}, n_{F}$, CPE coefficient (dimensionless).

High frequency loop is generally associated with the relaxation of the double layers capacitance in parallel with the charge- transfer resistance $[35,36]$. Home-made non-linear regression calculation based on Simplex algorithm was used to evaluate the value of each element defined in Figure 9.

Effective capacitances for the double layer $C_{d}$ and the faradaic capacitance $C_{F}$ were calculated instead of CPE ( $Q$ and $n$ ) according to the equation proposed by Brug et al. [37].

$$
C_{\text {eff }}=Q^{\frac{1}{n}} \cdot\left(\frac{1}{R_{1}}+\frac{1}{R_{2}}\right)^{\frac{n-1}{n}}
$$

The results of regression calculation are presented in Figure 10. No systematic error was observed during the calculation and $\chi$ value is, for three cases examined less than $0.6 \%$. The

$\chi$ value represents the mean error of real and imaginary part with respect to the impedance modulus, indicating the validity of the equivalent circuit model used here. 


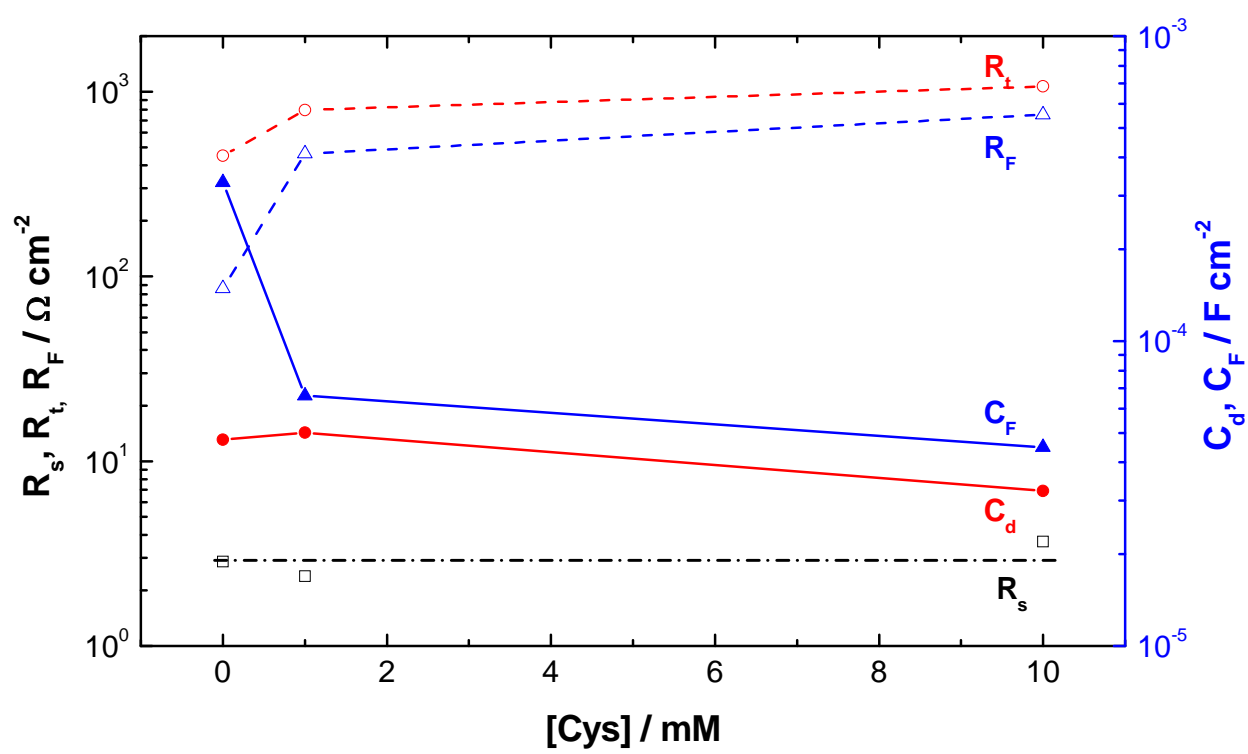

Figure 10: Variation of the polarization resistance $\left(R_{p}\right)$, the electrolyte resistance $\left(R_{s}\right)$, the double layer capacitance $\left(C_{d}\right)$ and the faradaic capacitance $\left(C_{F}\right)$ for Nickel in $0.5 \mathrm{M} \mathrm{H}_{2} \mathrm{SO}_{4}$ with and without of Cys

It can be seen in Figure 10 that the calculated electrolyte resistance $R_{s}$ is independent of experiments, and the average value is close to $3 \Omega \mathrm{cm}^{2}$. The value of $C_{d}$ decreases slightly in presence of Cys; $47 \mu \mathrm{F} \mathrm{cm}^{-2}$ in absence and $32 \mu \mathrm{F} \mathrm{cm}^{-2}$ in presence of $10 \mathrm{mM}$ Cys. These values are in good agreement with the double layer capacitance. The adsorption of Cys at nickel surface leads to only a slight decrease of the double layer capacitance. The cysteine being small and polar molecule, this is why the adsorption of this species at the nickel surface induces only a small decrease of the double layer capacitance. The value of $C_{F}$, which is directly related to the electrical charge stored on nickel surface. The peak potential is not very far from $E_{\text {corr }}$ as can be seen in Figure 5 , thus it is very likely that this capacitive behaviour is due to the relaxation of the reaction intermediate of active dissolution $\mathrm{NiOH}_{\mathrm{ad}}$ (Reaction 3) or that of passive species NiO (Reaction 5).

$C_{F}$ decreases steeply in presence of $1 \mathrm{mM}$ Cys then decreases slightly. In absence of this compound, $\mathrm{C}_{\mathrm{F}}$ is equal to $330 \mu \mathrm{F} \mathrm{cm}{ }^{-2}$, this capacitance becomes close to $70 \mu \mathrm{F} \mathrm{cm}{ }^{-2}$ at $1 \mathrm{mM}$ Cys and $45 \mu \mathrm{F} \mathrm{cm}{ }^{-2}$ at $10 \mathrm{mM}$ Cys. Therefore the presence of this molecule lessens the reversible species at the electrode surface. This will be the reason that the passive film in presence of cysteine is less protective than its absence as stated in §3.2. and \$3.3.2. 
The variation of the polarization resistance $R_{p}\left(=R_{t}+R_{F}\right)$, which corresponds to the chord of Nyquist plot, increase in presence of Cys. This increase is, however, moderate at $10 \mathrm{mM}$ Cys compared for instance for the case of the corrosion of Cu-Ni alloys by this molecule [26]. This result confirms a protective effect provided by cysteine against corrosion of nickel in an acid medium is weak since the corrosion rate is in major part controlled by the diffusion limiting current density of dissolved oxygen.

\subsection{Surface state after the corrosion test}

Inhibitive efficiency of cysteine evaluated by electrochemical methods is rather poor for nickel electrode in sulphuric acid solution whereas this molecule is efficient for copper-nickel alloy [26] and copper [24,36,38,39]. To verify if the effect of Cys, the surface state of the nickel electrode was observed by SEM after 24 hours immersion in $0.5 \mathrm{M} \mathrm{H}_{2} \mathrm{SO}_{4}$ in absence of in presence of Cys
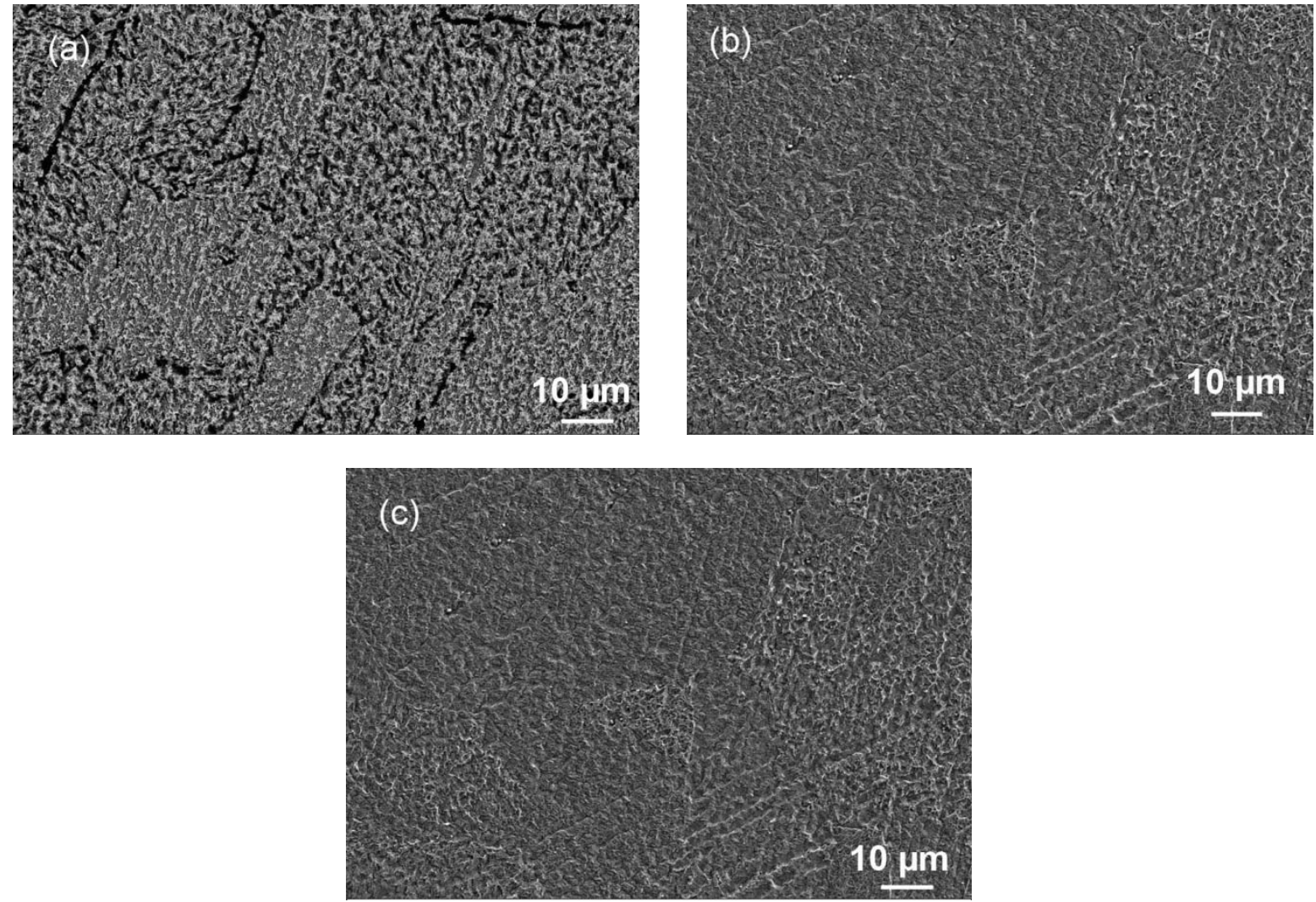

Figure 11: SEM images of the nickel surface after $24 \mathrm{~h}$ immersion in $0.5 \mathrm{M} \mathrm{H}_{2} \mathrm{SO}_{4}$;

(a) Without inhibitor, (b) with $1 \mathrm{mM}$ Cys and (c) with $10 \mathrm{mM}$ Cys 
Figure 11 presents the SEM pictures. It can be noticed that the electrode surface after the corrosion test is only slightly improved in presence of Cys corroborating the results obtained by electrochemical methods.

\subsection{Adsorption mechanism of cysteine}

As reported in the literature [40-42], inhibition efficiency depends on the number of adsorption sites in the molecule and their charge density, molecular size, and the mode of interaction with the metal surface. According to our results, the inhibition of nickel corrosion in sulphuric acid medium by Cys is moderate. At 1 or $10 \mathrm{mM}$, the corrosion efficiency is evaluated less than $30 \%$. If the adsorption of cysteine would decrease the reduction reaction of dissolved oxygen, and coupled with the decrease of anodic dissolution, one may expect a higher protective effectiveness. However, this is not the case; one may wonder why the results obtained in this study with Cys are so deficient compared to those reported for other systems, namely carbon steel or copper alloys. Other amino acids and organic compounds may give also a higher corrosion protection.

One of the reasons is probably due to the fact that, as it was reported [43] the nickel surface is positively charged in $\mathrm{H}_{2} \mathrm{SO}_{4}$ solution. Also in acid medium, the neutral Cys, will be protonated at the amino function $\left(\mathrm{HSCH}_{2} \mathrm{CH}\left(\mathrm{CO}_{2} \mathrm{H}\right) \mathrm{NH}^{3+}\right)$. Thus, it is difficult for the positively charged inhibitor molecules to approach the positively charged metal surface because of the electrostatic repulsion. Under these situations, the $\mathrm{SO}_{4}{ }^{2-}$ ions should first be adsorbed onto the anodic area, i.e. positively charged metal surface, creating negatively charged sites. After this preliminary step, the cysteine will be adsorbed by electrostatic interactions with negatively charged nickel surface at anodic sites. Thus, the positively charged inhibitor molecules form a protective film with $\mathrm{Ni}$-Cys complex as illustrated in Figure 12.

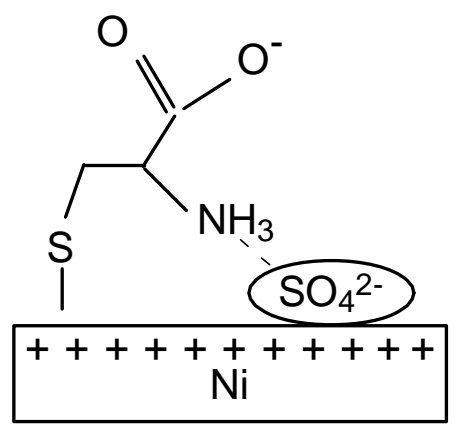

Figure 12: Schematic representation of Cys absorption. 
This process will induce a decrease of anodic current density as observed experimentally. With Figure 5 at $-0.61 V_{\text {SSE }}$ where the effect of cathodic current density becomes negligible in anodic polarization curve, it can be noticed that the current density is divided by 10 at $1 \mathrm{mM}$ Cys, and by 20 at 10 mM Cys. The cysteine is thus a good anodic inhibitor. In contrast, the NiCys complex film has little effect on the cathodic reduction rate of dissolved oxygen, and this process governs essentially the overall poor inhibitive efficiency.

\section{Conclusion}

The effect of cysteine molecule on the corrosion of nickel in $0.5 \mathrm{M} \mathrm{H}_{2} \mathrm{SO}_{4}$ solution was studied using electrochemical and SEM observation of corroded surface. Both voltammetric studies and impedance spectroscopy showed relatively poor inhibitory properties of this molecule. Cysteine decreases significantly the anodic current density, thus this molecule is an anodic-type inhibitor. The anodic Tafel slope decreases markedly by addition of cysteine, and suppress the first anodic current peak. The addition of cysteine in sulphuric acid modifies therefore the anodic process of nickel electrode. The impedance spectrum with faradaic capacitive behaviour is explained by the relaxation of anodic species, anodic reaction intermediate $\mathrm{NiOH}_{\mathrm{ad}}$ or the passive species leading to the first current peak $\mathrm{NiO}$. The decrease of the double layer capacitance in presence of cysteine in $\mathrm{H}_{2} \mathrm{SO}_{4}$ indicates its adsorption or the formation of $\mathrm{Ni}$-Cys complex on the metal surface. SEM images confirm a poor inhibitory effect of cysteine. 


\section{References}

1.P.A. Selembo, M.D. Merrill, B.E. Logan, The use of stainless steel and nickel alloys as low cost cathodes in microbial electrolysis cells. J. Power Sour 190, 271-278 (2009)

2. J.C. Grant, Nickel-Cadmium Battery Application Engineering Handbook, 3rd edn. (General Electric Company, Gainesville, 1975)

3. U.C. Nwaogu, C. Blawert, N. Scharnagl, W. Dietzel, K.U. Kainer, Influence of inorganic acid pickling on the corrosion resistance of magnesium alloy AZ31 sheet. Corros. Sci. 51, 25442556 (2009)

4. K.F. Khaled, Molecular modeling and electrochemical investigations of the corrosion inhibition of nickel using some thiosemicarbazone derivatives. J. Appl. Electrochem. 41, 423433 (2011)

5. A.A. Aksu"t, S. Bilgic, The effect of amino acids on the corrosion of nickel in $\mathrm{H}_{2} \mathrm{SO}_{4}$. Corros. Sci. 33, 379-387 (1992)

6. T. Arslan, F. Kandemirli, E.E. Ebenso, I. Love, H. Alemu, Quantum chemical studies on the corrosion inhibition of some sulphonamides on mild steel in acidic medium. Corros. Sci. 51, 35 (2009)

7. B.G. Ateya, M.B. Abo El-Khair, I.A. Abdel Hamed, Thiosemicarbazide as an inhibitor for the acid corrosion of iron. Corros. Sci. 16, 163-169 (1976)

8. H. Shokrya, E.M. Mabrouk, Computational and electrochemical investigation for corrosion inhibition of nickel in molar sulfuric acid by dihydrazide derivatives. Part II. Arab. J. Chem. 10, S3402-S3411 (2017)

9. C.F. Zinola, A.M. Castro Luna, The inhibition of $\mathrm{Ni}$ corrosion in $\mathrm{H}_{2} \mathrm{SO}_{4}$ solutions containing simple non-saturated substances. Corros. Sci. 37, 1919-1929 (1995)

10. A. Samide, I. Bibicu, A new inhibitor for corrosion of carbon steel in hydrochloric acid solution. Rev. Roum. Chim. 54, 33-43 (2009)

11. P.C. Okafor, C.B. Liu, X. Liu, Y.G. Zheng, F. Wang, C.Y. Liu, F. Wangm, Corrosion inhibition and adsorption behavior of imidazoline salt on $\mathrm{N} 80$ carbon steel in $\mathrm{CO}_{2}$-saturated solutions and its synergism with thiourea. J. Solid State Electrochem. 14, 1367- 1376 (2010).

12.S. Gowri, J. SathiyabamA, S. Rajendran, Corrosion inhibition by amino acids-an over review. Eur. Chem. Bull. 11, 470-476 (2012).

13. H. El Attari, K. Chefira, M. Siniti, A. El Kihel, H. Rchid, Adsorption and corrosion inhibition performance of 1,3-dihydro- 2Hbenzimidazole-2-thione for mild steel C35 E in sulfuric acid solution. Int. J. Recent Trends Eng. Res. (IJRTER) 03, 2455- 2457 (2017).

14. H.I. Taleb, A.Z. Mohamed, Corrosion inhibition of mild steel using fig leaves extract in hydrochloric acid solution. Int. J. Electrochem. Sci. 6, 6442-6455 (2011).

15. M. Bethencourt, F.J. Botana, J.J. Calvino, M. Marcosm, Lanthanide compounds as environmentally-friendly corrosion inhibitors of aluminium alloys. Corros. Sci. 40, 1803-1819 (1998).

16. M.A. Arenas, A. Conde, J.J. De Damborenea, Cerium: a suitable green corrosion inhibitor for tinplate. Corros. Sci. 44, 511- 520 (2002).

17. S.M. El-Sawy, Y.M. Abu-Ayana, F.A. Abdel-Mohdy, Some chitin/chitosan derivatives for corrosion protection and waste water treatments. Anticorros. Methods Mater. 48, 227-235 (2001).

18. P.B. Raja, M.G. Sethuraman, Natural products as corrosion inhibitor for metals in 
19. corrosive media (a review). Mater. Lett. 62, 113-116 (2008). H. Tian, W. Li, K. Cao, B. Hou, Potent inhibition of copper corrosion in neutral chloride media by novel non-toxic thiadiazole derivatives. Corros. Sci. 73, 281-291 (2013).

20. G. Moretti, F. Guidi, G. Grion, Tryptamine as a green iron corrosion inhibitor in $0.5 \mathrm{M}$ deaerated sulphuric acid. Corros. Sci. 46, 387 (2004)

21. G. Moretti, F. Guidi, Tryptophan as copper corrosion inhibitor in $0.5 \mathrm{M}$ aerated sulfuric acid. Corros. Sci. 44, 1995-2011 (2002).

22. W. Yang, J.J. Gooding, D.B. Hibbert, Characterisation of gold electrodes modified with self-assembled monolayers of L-cysteine for the adsorptive stripping analysis of copper. J. Electroanal. Chem. 516, 10-16 (2001)

23. J.B. Matos, L.P. Pereira, S.M.L. Agostinho, O.E. Barcia, G.G.O. Cordeiro, E. D’Elia, Effect of cysteine on the anodic dissolution of copper in sulfuric acid medium. J. Electroanal. Chem. 570, 91- 94 (2004)

24. K.M. Ismail, Evaluation of cysteine as environmentally friendly corrosion inhibitor for copper in neutral and acidic chloride solutions. Electrochim. Acta 52, 7811-7819 (2007) 25. A.B. Silva, S.M.L. Agostinho, O.E. Barcia, G.G.O. Cordeiro, E. D’Elia, The effect of cysteine on the corrosion of $304 \mathrm{~L}$ stainless steel in sulphuric acid. Corros. Sci. 48, 3668-3674 (2006) 26. H. Saifi, M.C. Bernard, S. Joiret, K. Rahmouni, H. Takenouti, B. Talhi, Corrosion inhibitive action of cysteine on $\mathrm{Cu}-30 \mathrm{Ni}$ alloy in aerated 0.5 M H2SO4. Mater. Chem. Phys. 120, 661669 (2010)

27. M. Abdallah, A.Y. El-Etre, Corrosion inhibition of nickel in sulfuric acid using tween surfactants. Port. Electrochim. Acta 21, 315-326 (2003).

28. W.J. Lorenz, F. Mansfeld, Determination of corrosion rates by electrochemical DC and AC methods. Corros. Sci. 21, 647-672 (1981)

29. T.S. De Gromoboy, L.L. Shreir, The formation of nickel oxides during the passivation of nickel in relation to the potential/pH diagram. Electrochim. Acta 11, 895 (1966)

30. F. Said, N. Souissi, K. Es-Salah, N. Hajjaji, E. Triki, A. Srhiri, Phosphonium iodine as nickel corrosion inhibitor in $1 \mathrm{M}$ sulphuric acid medium. J. Mater. Sci. 42, 9070-9074 (2007)

31. K.F. Khaled, M.A. Amin, Computational and electrochemical investigation for corrosion inhibition of nickel in molar nitric acid by piperidines. J. Appl. Electrochem. 38, 1609-1621 (2008)

32. V.V. Parshutin, N.L. Bogdashkina, G.P. Chernova, The effect of medium on the corrosion and electrochemical behavior of nickel. Prot. Met 43, 59-65 (2007)

33. B.A. Abd-El-Nabey, A.M. Abdel-Gaber, M. El, E. Said Ali, S.El- Housseiny Khamis, Cannabis plant extract as inhibitor for thecorrosion of nickel in $0.5 \mathrm{M} \mathrm{H} 2 \mathrm{SO}$. Int. J. Electrochem. Sci. 7, 11811-11826 (2012)

34. M. Stern, A.L. Geary, Electrochemical polarization. I A theoretical analysis of the shape of polarization curves. J. Electrochem. Soc. 104, 56 (1957)

35. B. Mezhoud, M. Bouchouit, M.E. Said, L. Messaadia, A. Belfaitah, H. Merazig, A. Chibani, S. Bouacida, A. SofianeBouraiou, Synthesis, $x$-ray structure and theoretical study of benzazole thioether and its zinc complex as corrosion inhibitors for steel in acidic medium. Res. Chem. Intermed. 42, 7447-7470 (2016)

36. D.-Q. Zhang, Q.-R. Cai, L.-X. Gao, K.Y. Lee, Effect of serine, threonine and glutamic acid on the corrosion of copper in aerated hydrochloric acid solution. Corros. Sci. 50, 3615-3621 (2008) 
37. G.J. Brug, A.L.G. Van den Eeden, M. Sluyters-Rehbach, J.H. Sluyters, The analysis of electrode impedances complicated by the presence of a constant phase element. J.

Electroanal.176, 275-295 (1984)

38. D.Q. Zhang, L.X. Gao, G.D. Zhou, Inhibition of copper corrosion in aerated hydrochloric acid solution by amino-acid compounds.J. Appl. Eletrochem. 35, 1081 (2005)

39. M.B. Petrovic', M.B. Radovanovic', A.T. Simonovic', S.M. Milic', M.M. Antonijevic', The effect of cysteine on the behaviour of copper in neutral and alkaline sulphate solutions. Int. J. Electrochem. Sci. 7, 9043-9905 (2012)

40. C. Monticelli, G. Brunoro, A. Frignani, F. Zucchi, Surface-active substances as inhibitors of localized corrosion of the aluminium

41. Q.B. Zhang, Y.X. Hua, Corrosion inhibition of Mild steel by alkylimidazolium ionic liquids in hydrocholoric acid. Electrochim. Acta 54, 1881-1887 (2009)

42. A.A. El-shafei, M.N.H. Moussa, A.A. El-Far, Inhibitory effect of amino acids on Al pitting corrosion in $0.1 \mathrm{M} \mathrm{NaCl}$. J. Appl. Electrochem. 27, 1075 (1997)

43. E. Hamed, S.S. Abd El-REhim, M.F. El-Shahat, A.M. Shaltot, Corrosion inhibition of nickel in $\mathrm{H}_{2} \mathrm{SO}_{4}$ solution by alanine. Mater. Sci. Eng., B 177, 441-448 (2012). 